\title{
Delirium after surgical and transcatheter aortic valve replacement is associated with increased mortality
}

\author{
Hersh S. Maniar, MD, ${ }^{a}$ Brian R. Lindman, MD, ${ }^{b}$ Krisztina Escallier, MD, ${ }^{c}$ Michael Avidan, MD, ${ }^{c}$ \\ Eric Novak, MS, ${ }^{\mathrm{b}}$ Spencer J. Melby, MD, ${ }^{\mathrm{a}}$ Marci S. Damiano, RN, MSN, ${ }^{\mathrm{b}}$ John Lasala, MD, ${ }^{\mathrm{b}}$ \\ Nishath Quader, MD, ${ }^{\mathrm{b}}$ Ravinder Singh Rao, MD, ${ }^{\mathrm{b}}$ Jennifer Lawton, MD, ${ }^{\mathrm{a}}$ Marc R. Moon, MD, \\ Daniel Helsten, MD, ${ }^{\mathrm{c}}$ Michael K. Pasque, MD, ${ }^{\mathrm{a}}$ Ralph J. Damiano, Jr, MD, ${ }^{\mathrm{a}}$ and Alan Zajarias, $\mathrm{MD}^{\mathrm{b}}$
}

\section{ABSTRACT}

Objective: The purpose of this study was to determine the incidence and clinical significance of postoperative delirium (PD) in patients with aortic stenosis undergoing surgical aortic valve replacement (SAVR) or transcatheter aortic valve replacement (TAVR).

Method: Between 2010 and 2013, 427 patients underwent TAVR $(\mathrm{n}=168)$ or SAVR $(n=259)$ and were screened for PD using the Confusion Assessment Method for the Intensive Care Unit. The incidence of PD in both treatment groups was determined and its association with morbidity and mortality was retrospectively compared.

Results: PD occurred in 135 patients $(32 \%)$ with a similar incidence between SAVR $(33 \%$ [86 out of 259]) and TAVR $(29 \%$ [49 out of 168]) $(P=.40)$. TAVR by transfemoral approach had the lowest incidence of PD compared with SAVR $(18 \%$ vs $33 \% ; P=.025)$ or TAVR when performed by alternative access techniques ( $18 \%$ vs $35 \% ; P=.02)$. Delirium was associated with longer initial intensive care unit stay (70 vs 27 hours), intensive care unit readmission (10\% [14 out of 135] vs $2 \%$ [ 6 out of 292]), and longer hospital stay ( 8 vs 6 days) $(P<.001$ for all). PD was associated with increased mortality at 30 days (7\% vs $1 \%$; $P<.001)$ and 1 year $(21 \%$ vs $8 \% ; P<.001)$. After multivariable adjustment, $\mathrm{PD}$ remained associated with increased 1-year mortality (hazard ratio, 3.02; $95 \%$ confidence interval, 1.75-5.23; $P<.001$ ). There was no interaction between PD and aortic valve replacement approach with respect to 1-year mortality $(P=.12)$. Among propensity-matched patients $(\mathrm{n}=170)$, SAVR-treated patients had a higher incidence of PD than TAVR-treated patients $(51 \%$ vs $29 \%$; $P=.004)$.

Conclusions: PD occurs commonly after SAVR and TAVR and is associated with increased morbidity and mortality. Given the high incidence of PD and its associated adverse outcomes, further studies are needed to minimize PD and potentially improve patient outcomes. (J Thorac Cardiovasc Surg 2016;151:815-23)

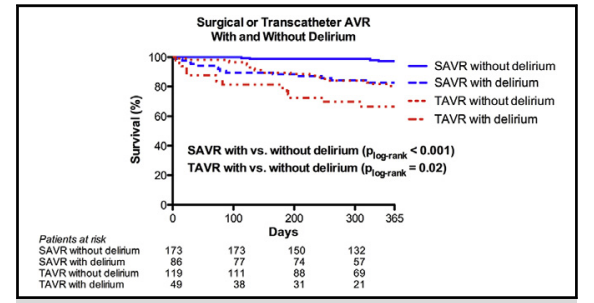

Surgical aortic valve replacement and transcatheter aortic valve replacement with and without delirium.

Central Message

Delirium after surgical and transcatheter aortic valve replacement is associated with increased mortality.

\section{Perspective}

Postoperative delirium was assessed in patients undergoing surgical and transcatheter aortic valve replacement. The development of postoperative delirium was associated with increased perioperative morbidity as well as both early and 1-year mortality.

See Editorial Commentary page 823 .

\footnotetext{
From the ${ }^{\mathrm{a} D i v i s i o n}$ of Cardiothoracic Surgery, Department of Surgery; ${ }^{\mathrm{b}}$ Division of Cardiology, Department of Medicine; and ${ }^{\mathrm{c}}$ Department of Anesthesia, Barnes Jewish Hospital/Washington University School of Medicine, St Louis, Mo.

Supported by grant BJHF\#7937-77 from the Barnes-Jewish Hospital Foundation. BRL is supported by grant No. K23 HL116660 from the National Institutes of Health.

Read at the 95th Annual Meeting of The American Association for Thoracic Surgery, Seattle, Washington, April 25-29, 2015.

Received for publication May 16, 2015; revisions received Oct 11, 2015; accepted for publication Oct 21, 2015; available ahead of print Jan 13, 2016.

Address for reprints: Hersh S. Maniar, MD, Divisions of Cardiothoracic Surgery and Cardiology, Barnes-Jewish Hospital/Washington University School of Medicine,

One Barnes-Jewish Plaza, Queeny Tower Ste 3108, St Louis, MO 63108 (E-mail: maniarh@wudosis.wustl.edu).

$0022-5223 / \$ 36.00$

Copyright (c) 2016 by The American Association for Thoracic Surgery

http://dx.doi.org/10.1016/j.jtcvs.2015.10.114
}

Postoperative delirium (PD) is a well-recognized complication after cardiac surgery defined as an acute and fluctuating neurologic disorder that reflects a change from baseline cognition and is characterized by the cardinal features of inattention and disorganized thinking. ${ }^{1} \mathrm{PD}$ is more common

Scanning this QR code will take you to the article supplemental figures and table. To view the AATS 2015 Webcast, see the URL at the end of the article. 


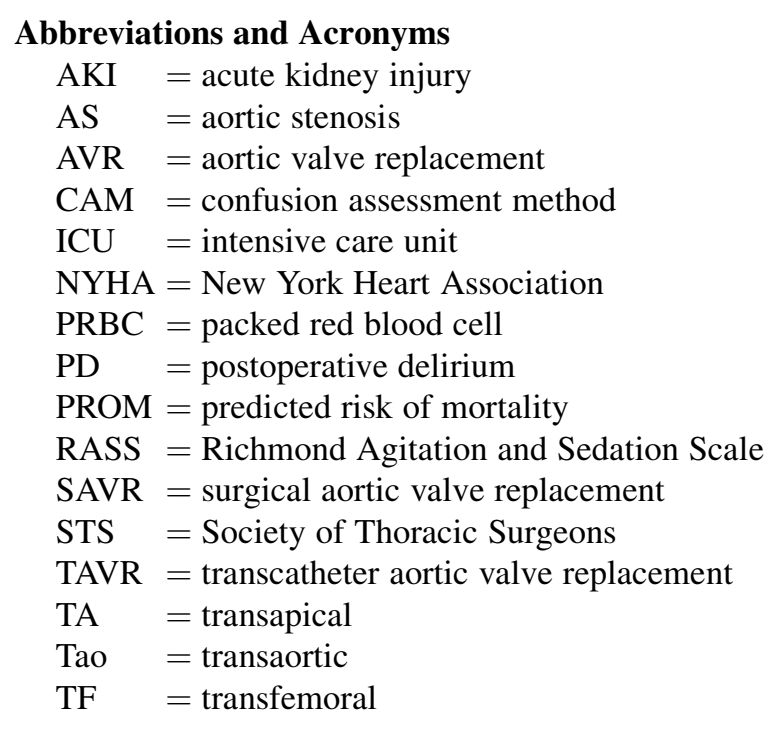

in patients older than age 65 years and has an estimated incidence between $25 \%$ and $50 \%$ after cardiac surgery, which translates into more than 120,000 patients affected per year in the United States alone. ${ }^{2-4}$ Although efforts to detect PD have increased during the past decade, it remains underestimated in many clinical settings. Moreover, as older and frailer patients increasingly undergo major procedures, the incidence of PD is likely to increase substantially during the next decade. ${ }^{5}$

PD after traditional cardiac surgery has been associated with increased morbidity, longer hospital length of stay, and greater mortality. ${ }^{6-8}$ These negative outcomes have resulted in increased health care costs estimated at $\$ 150$ billion annually. ${ }^{9}$ Although the influence of PD on shortterm and perioperative outcomes seems intuitive, PD has additionally been linked to late cognitive impairments that persist at intermediate and long-term follow-up. ${ }^{4,10}$ Multiple studies have focused on treating PD, but most have had limited success, resulting in a greater emphasis placed upon the prevention of PD and the identification of risk factors for its development. ${ }^{5}$

Recent advances in the treatment of patients with severe aortic stenosis (AS), specifically in the area of transcatheter aortic valve replacement (TAVR) now allow for aortic valve replacement (AVR) procedures to be performed without the need for cardiopulmonary bypass, requiring fewer transfusions, and in many cases, without even a surgical incision or general anesthesia. ${ }^{11,12}$ As such, TAVR procedures minimize or eliminate many of the traditional factors associated with the development of PD after conventional AVR surgery. Although several large trials have evaluated outcomes after TAVR in comparison to surgical aortic valve replacement (SAVR), there are fewer data available regarding the use of TAVR and its association with PD and subsequent sequelae.

The purpose of this study was to compare the incidence of PD after TAVR and SAVR, examine the adverse outcomes associated with PD, and explore possible risk factors for the development of PD after either procedure. We hypothesized that the incidence of PD would be lower after TAVR than SAVR, would be associated with increased mortality after either procedure, and would be associated with different risk factors for its development within each treatment population.

\section{METHODS}

In this retrospective study from 2010 to 2013 , we included all patients with severe AS who underwent an isolated AVR procedure at BarnesJewish Hospital in whom PD was assessed with the Confusion Assessment Method for the Intensive Care Unit (CAM-ICU). Severe AS was defined as an indexed aortic valve area $<0.6 \mathrm{~cm}^{2} / \mathrm{m}^{2}$, a mean gradient $>40 \mathrm{~mm} \mathrm{Hg}$, or a maximum jet velocity $>4.0 \mathrm{~m} / \mathrm{sec}$. Patients were offered TAVR in the setting of a clinical trial or if they met TAVR eligibility criteria once TAVR became approved for use by the US Food and Drug Administration. A total of 427 patients were treated with either TAVR $(n=168)$ or SAVR $(\mathrm{n}=259)$.

This study was written in compliance with Strengthening the Reporting of Observational studies in Epidemiology guidelines and approved by the local institutional review board from which a waiver of written informed consent was obtained given the retrospective design of the study.

\section{TAVR and SAVR Approaches}

The TAVR procedures have previously been described ${ }^{11}$ and were performed via a transfemoral (TF) approach when femoral access was suitable $(\mathrm{n}=57)$. In cases where TAVR-TF was not possible, TAVR was performed either by a direct aortic (TAo) $(n=37)$ or transapical (TA) $(\mathrm{n}=74)$ approach. All procedures were performed under general anesthesia and all TF approaches were performed using surgical femoral exposure. SAVR procedures were performed via limited or full sternotomy using cardiopulmonary bypass and myocardial arrest.

\section{Anesthetic Approach for TAVR and SAVR}

General anesthesia was typically induced with propofol, fentanyl, and rocuronium. A limited use of benzodiazepines was not uncommon. All patients had endotracheal tubes placed and were mechanically ventilated for the procedure. Anesthesia was maintained with a balanced anesthetic technique, including a potent inhaled agent and titration of opioid analgesics. Transesophageal echocardiography was performed in all cases. Intraoperative data, including vital signs and medications, were automatically archived every minute by an electronic anesthetic record system (Metavision; IMDsoft, Needham, Mass). Volatile anesthetic concentrations were converted into age-adjusted minimum alveolar concentration equivalents, ${ }^{13}$ summed across all volatile anesthetic agents.

\section{Delirium Assessment}

After the AVR procedure, all patients were admitted to an intensive care unit (ICU), where clinical nurses trained in the administration of the CAM-ICU assessed patients for PD every 12 hours using the CAM-ICU. The CAM-ICU assessment has been a routine part of the standard postoperative nursing assessment of all cardiac surgical patients since its introduction in 2010. Although the CAM-ICU was developed for nonverbal ICU patients, it has also been shown to be specific and reasonably sensitive in nonintubated ICU patients. ${ }^{14,15}$ The tool is based on operationalized 
criteria derived from the Diagnostic and Statistical Manual of Mental Disorders and assesses 4 features: acute-onset and fluctuating course, inattention, disorganized thinking, and altered level of consciousness. The CAM-ICU assessment was positive for delirium when both acute-onset and fluctuating course and inattention, and either disorganized thinking or altered level of consciousness were present (http://www. icudelirium.org/docs/CAM_ICU_training.pdf). Patients were identified as having PD if they had at least 1 positive CAM-ICU assessment during their ICU stay.

Delirium episodes were further classified as hypoactive, hyperactive, or mixed by using the Richmond Agitation and Sedation Scale (RASS) documented at the time of the delirium assessment. ${ }^{16,17}$ The RASS is a 10-point sedation scale that measures level of consciousness. A RASS of 0 reflects an alert and calm patient, whereas scores $>0$ indicate increasing agitation, and scores $<0$ indicate deepening sedation. RASS scores were documented every 4 hours in the ICU and the corresponding RASS score within 12 hours of a given CAM-ICU assessment (the 6 hours before and after the assessment) was used to assess delirium phenotype. When patients were CAM-ICU positive, a RASS consistently $>0$ was indicative of hyperactive delirium, a RASS consistently $<0$ was indicative of hypoactive delirium, and for patients exhibiting scores both $>0$ and $<0$, the delirium phenotype was considered mixed.

All perioperative data, including Society of Thoracic Surgeons database variables, intraoperative monitoring data, delirium, and RASS assessments were prospectively collected within institutional databases and subsequently retrospectively reviewed for perioperative outcomes.

\section{Statistical Analyses}

Descriptive statistics were determined for TAVR and SAVR patients separately. Comparisons between groups were done using Student $t$ test for continuous variables and Fisher exact test for categorical variables. Nonnormal and ordinal variables were summarized as median (first quartile, third quartile) and compared via the Kruskal-Wallis test.

Propensity score matching was used to compare PD rates between TAVR and SAVR patients. A logistic regression model was used to create the probability that patient was assigned to TAVR for treatment using the following variables: age, gender, Society of Thoracic Surgeons score, New York Heart Association (NYHA) functional class III or IV (vs I or II), diabetes mellitus, coronary artery disease, peripheral vascular disease, cerebrovascular disease, moderate/severe lung disease, glomerular filtration rate, and hemoglobin. An optimal matching algorithm with caliper set to 0.05 was used to create a 1:1 matched sample. Delirium rates were compared within the matched sample using McNemar test (Figures $\mathrm{E} 1$ and $\mathrm{E} 2)$.

Mortality was evaluated using time to event analysis. Start time was date of the AVR procedure and patients were followed until event occurrence or last available follow-up, to 1 year. Kaplan-Meier curves were created by delirium status and compared using the log-rank test. Additional multivariable Cox proportional hazards regression models were created to evaluate the association between delirium and 1-year mortality while adjusting for AVR approach, age, sex, and STS predicted risk of mortality (STS-PROM) score; the interaction between PD and AVR approach was assessed. These covariates were selected a priori based on their known association with mortality. Within AVR approach, the rates of occurrence for prolonged ventilation, stroke, acute kidney injury (AKI), and ICU readmission were individually compared between delirium groups using Fisher exact test. AKI was defined in accordance with Valve Academic Research Consortium-2 criteria. ${ }^{18}$ Thirty-day and 1-year Kaplan-Meier estimates for survival were compared using a $z$ test. The Kruskal-Wallis test was used to compare initial ICU and hospital length of stay.

Multivariable logistic regression models were built to explore predictors of delirium within TAVR and SAVR patients separately. Variables for inclusion within the multivariable models were selected based on a univariable cutoff $P$ value of $<.1$. The number of variables included in the models was limited based on the incidence of PD in each cohort. The variables age, STS-PROM, steroid use, TAVR approach, and intraoperative packed red blood cell (PRBC) transfusions, were entered into the TAVR model. For SAVR patients, the variables included age, STS-PROM, previous percutaneous coronary intervention, NYHA functional class $\geq$ III, moderate/severe lung disease, hemoglobin, moderate/severe mitral regurgitation, intraoperative PRBC use, intra-aortic balloon pump, and intubation time. These models evaluated the association between each variable and PD while adjusting for other model variables.

All analyses were conducted using SAS version 9.4 (SAS Institute Inc, Cary, NC).

\section{RESULTS \\ Demographic and Intraoperative Differences Between TAVR and SAVR}

When compared with SAVR, patients undergoing TAVR were significantly older, had greater frequencies of comorbidities of nearly all measured variables, were of worse functional class by American Society of Anesthesiologists score, and had higher predicted risks of mortality by the STS-PROM (Table 1).

Intraoperatively, whereas TAVR procedures were shorter in duration $(153 \pm 58$ minutes vs $253 \pm 73$ minutes; $P=.001)$ these patients received a higher mean minimum alveolar concentration of volatile anesthetic than patients undergoing SAVR $(0.95 \pm 0.13$ vs $0.86 \pm 0.11$; $P<.001)$. PRBC transfusions $(67 \%$ vs $40 \% ; P<.001)$ and tranexamic acid administration $(93 \%$ vs $2 \%$; $P<.001)$ were more frequent during SAVR procedures.

\section{Delirium Incidence in TAVR and SAVR}

For the entire study, PD was identified in 135 patients (32\%; 95\% confidence interval $[\mathrm{CI}], 27 \%-36 \%$ ). Hypoactive delirium was the most common subtype, encountered in 71 patients $(53 \%) ; 64$ patients $(47 \%)$ presented with a mixed phenotype; and no patient consistently had hyperactive delirium. The incidence of PD after TAVR was not significantly different than after SAVR ( $29 \%$ vs $33 \%$; odds ratio [OR], $0.82 ; 95 \%$ CI, $0.54-$ $1.26 ; P=.40$ ); however within the subset of TAVR, patients undergoing TAVR-TF had an $18 \%$ incidence of PD, the lowest incidence of any AVR approach. The incidence of PD after TAVR-TF was significantly lower when compared with SAVR (18\% vs $33 \%$; OR, 0.43 ; $95 \%$ CI, $0.21-0.89 ; P=.025)$ or TAVR when performed using alternative access (ie, TA or TAo) techniques $(18 \%$ vs $35 \%$; OR, $0.39 ; 95 \%$ CI, 0.18-0.86; $P=.020$ ). After propensity matching, $29 \%$ ( 25 out of 85 ) of the TAVRtreated patients and $51 \%$ (43 out of 85 ) of the SAVRtreated patients developed PD $(P=.004)$.

\section{Perioperative Complications and Mortality}

Table 2 shows univariable associations between delirium and postoperative complications. For both TAVR and SAVR patients, PD was associated with a longer ICU and hospital length of stay. For SAVR specifically, there were additional 
TABLE 1. Baseline characteristics of patients undergoing transcatheter aortic valve replacement (TAVR) and surgical aortic valve replacement (SAVR)

\begin{tabular}{|c|c|c|c|}
\hline Characteristic & $\begin{array}{c}\text { TAVR } \\
(n=168)\end{array}$ & $\begin{array}{c}\text { SAVR } \\
(n=259)\end{array}$ & $\begin{array}{c}P \\
\text { value }\end{array}$ \\
\hline Age (y) & $81 \pm 8$ & $71 \pm 11$ & $<.001$ \\
\hline Female & $92(55)$ & $108(42)$ & .010 \\
\hline Body mass index & $27.5 \pm 6.3$ & $31 \pm 8$ & $<.001$ \\
\hline $\begin{array}{l}\text { Society of Thoracic Surgeons } \\
\text { predicted risk of mortality } \\
\text { score }\end{array}$ & $9.3(6.1,13.5)$ & $3.0(1.5,6.0)$ & $<.001$ \\
\hline $\begin{array}{l}\text { American Society of } \\
\text { Anesthesiologists class } \geq 4\end{array}$ & $162(96)$ & $180(70)$ & $<.001$ \\
\hline $\begin{array}{l}\text { New York Heart Association } \\
\text { functional class III-IV }\end{array}$ & $147(88)$ & $139(54)$ & $<.001$ \\
\hline Diabetes mellitus & $72(43)$ & $95(37)$ & .220 \\
\hline Hypertension & $156(93)$ & $209(81)$ & $<.001$ \\
\hline Coronary artery disease & $143(85)$ & $114(44)$ & $<.001$ \\
\hline Cerebrovascular disease & $52(31)$ & $57(22)$ & .040 \\
\hline Atrial fibrillation & $65(39)$ & $49(19)$ & $<.001$ \\
\hline Chronic lung disease* & $59(35)$ & $39(15)$ & $<.001$ \\
\hline Peripheral vascular disease & $113(67)$ & $71(27)$ & $<.001$ \\
\hline Ejection fraction (\%) & $53 \pm 15$ & $58 \pm 14$ & .002 \\
\hline $\begin{array}{l}\text { Mean aortic valve gradient } \\
\qquad(\mathrm{mm} \mathrm{Hg})\end{array}$ & $44 \pm 14$ & $43 \pm 14$ & .700 \\
\hline $\begin{array}{l}\text { Preoperative glomerular filtration } \\
\text { rate }(\mathrm{mL} / \mathrm{min})\end{array}$ & $64 \pm 27$ & $75 \pm 26$ & $<.001$ \\
\hline Hemoglobin (g/dL) & $11.3 \pm 1.5$ & $12.5 \pm 1.9$ & $<.001$ \\
\hline Albumin $(\mathrm{g} / \mathrm{dL})$ & $4.0 \pm 0.5$ & $4.1 \pm 4$ & .120 \\
\hline
\end{tabular}

Values are presented as mean \pm standard deviation, $\mathrm{n}(\%)$, or median (first quartile, third quartile). TAVR, Transcatheter aortic valve replacement; SAVR, surgical aortic valve replacement. *Moderate/severe.

complications associated with PD that included prolonged ventilation, and a greater need for readmission to the ICU. PD after TAVR and SAVR was associated with an increased likelihood that at hospital discharge, patients required transfer to an extended care facility, and were less likely to be discharged to home. These associations between PD and AKI, discharge location, ICU time and hospital length of stay all remained unchanged even after adjustment by STS-PROM score.
In unadjusted analyses, the development of PD after SAVR or TAVR was associated with increased mortality over the first year for either procedure (Figure 1). For TAVR patients without PD, survival was better at 30 days (98\% vs $88 \% ; P=.029)$ and tended to be better at 1 year $(80 \%$ vs $66 \% ; P=.09)$ based on Kaplan-Meier estimates. Similarly for SAVR, Kaplan-Meier estimates of survival were better for patients without PD at both 30 days $(100 \%$ vs $95 \% ; P=.04)$ and 1 year $(97 \%$ vs $83 \% ; P=.001)$, respectively. By multivariable analysis, after adjusting for age, sex, STS-PROM score, and AVR type, PD was associated with increased risk of mortality through the first year after AVR for the entire study population $(\mathrm{n}=427)$ (hazard ratio [HR], 3.02; 95\% CI, 1.75-5.23; $P<.001$ ) (Table 3). PD additionally remained significantly associated with increased risk of mortality within both TAVR (HR, 2.02; 95\% CI, 1.12-4.35) and SAVR groups (HR, 6.28; 95\% CI, 2.04-19.31) after similarly adjusting for age, sex, and STS-PROM score. There was also no significant interaction between AVR type (TAVR vs SAVR) and PD with respect to 1-year mortality (interaction $P=.12$ ), indicating that the relationship between PD and post-AVR mortality was similar for patients treated with TAVR and SAVR.

\section{Predictors of Delirium After TAVR and SAVR}

Univariable associations with PD for patients undergoing both TAVR and SAVR are shown in Table 4. The use of a non-TF approach $(P=.013)$ and preoperative steroid use $(8 \%$ vs $24 \% ; P=.004)$ were associated with the development of PD after TAVR, whereas for SAVR, the development of PD was associated with increasing age, elevated STS-PROM score, worse American Society of Anesthesiologists score, NYHA functional class III or IV, and the presence of specific comorbidities such as coronary artery disease and chronic lung disease. PD was seen more frequently in patients with lower preoperative hemoglobin levels and, similar to TAVR, PD was more frequent when PRBC transfusions were required intraoperatively.

TABLE 2. Perioperative morbidity and mortality for patients undergoing transcatheter aortic valve replacement (TAVR) and surgical aortic valve replacement (SAVR)

\begin{tabular}{|c|c|c|c|c|c|c|}
\hline \multirow[b]{2}{*}{ Event } & \multicolumn{3}{|c|}{ TAVR } & \multicolumn{3}{|c|}{ SAVR } \\
\hline & No delirium $(n=119)$ & Delirium $(n=49)$ & $P$ value & No delirium $(n=173)$ & Delirium $(n=86)$ & $P$ value \\
\hline Prolonged ventilation & $2(2)$ & $0(0)$ & $>.999$ & $10(6)$ & $18(21)$ & $<.001$ \\
\hline Stroke & $1(1)$ & $1(2)$ & .500 & $1(1)$ & $1(1)$ & $>.999$ \\
\hline Acute kidney injury & $8(7)$ & $12(24)$ & .003 & $25(14)$ & $15(17)$ & .580 \\
\hline Initial intensive care unit stay (h) & 26 & 50 & $<.001$ & 31 & 72 & $<.001$ \\
\hline Readmission to the intensive care unit & $4(3)$ & $5(10)$ & .120 & $2(1)$ & $9(10)$ & .001 \\
\hline Hospital length of stay (d) & 5 & 7 & $<.001$ & 7 & 9 & $<.001$ \\
\hline Discharged to home & $87(73)$ & $26(53)$ & .018 & $146(84)$ & $49(57)$ & $<.001$ \\
\hline $30-d$ survival $(\%)$ & 98 & 88 & .029 & 100 & 95 & .040 \\
\hline 1-y survival (\%) & 80 & 66 & .090 & 97 & 83 & .001 \\
\hline
\end{tabular}

Values are presented as n (\%) unless otherwise noted. TAVR, Transcatheter aortic valve replacement; $S A V R$, surgical aortic valve replacement. 


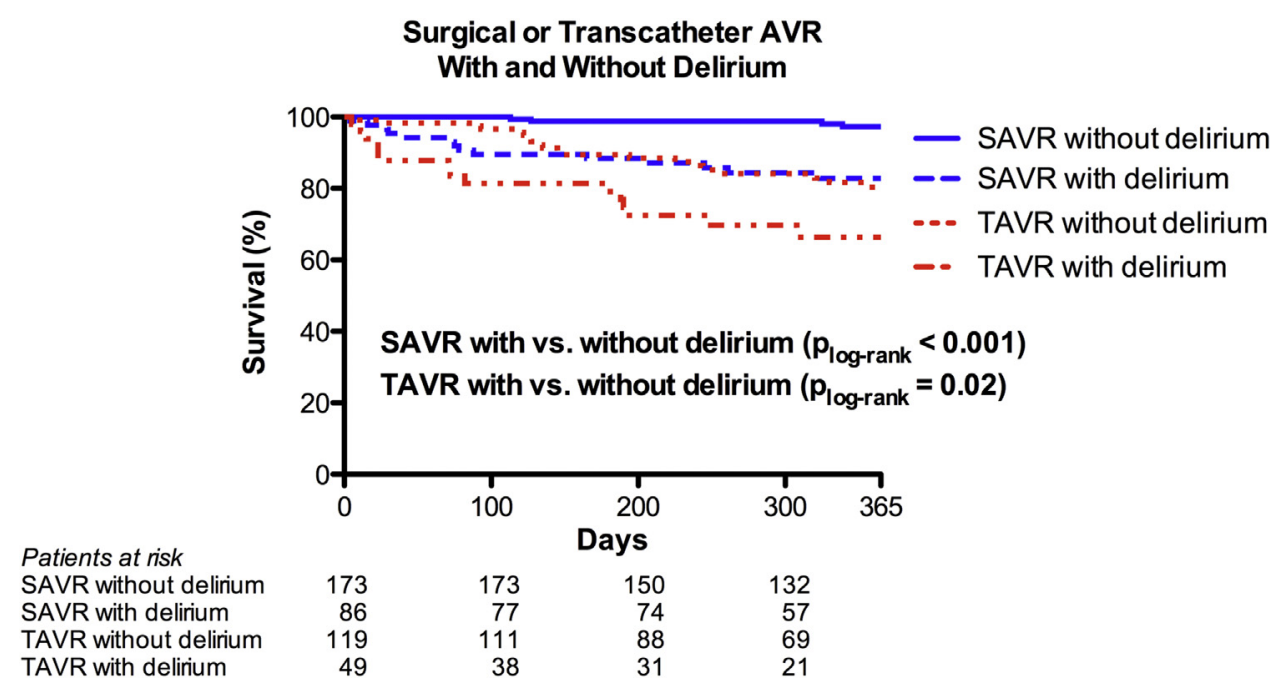

FIGURE 1. Time to even curves for 1-year death from any cause. One year time to event curves are shown for patients treated with surgical aortic valve replacement $(S A V R)$ and transcatheter aortic valve replacement $(T A V R)$ with and without delirium. Within each treatment group, patients with and without delirium were compared with the use of the log-rank test. $A V R$, Aortic valve replacement.

Specifically for SAVR, there were no differences in PD with respect to cardiopulmonary bypass $(110 \pm 37$ vs $108 \pm 25$; $P=.63)$ or aortic crossclamp times $(76 \pm 23$ vs $72 \pm 18$; $P=.15)$. Procedural time was not a factor for PD for either TAVR or SAVR.

The independent predictors for the development of delirium are shown in Tables 5 and 6. Within the SAVR cohort, the independent predictors for the development of PD were age, and the presence of concomitant valvular heart disease, specifically mitral regurgitation. An intubation period $<24$ hours after SAVR was associated with less PD (Table 5). For TAVR, no specific comorbidities were identified as independent predictors for PD with only preoperative steroid use and the development of AKI postoperatively remaining statistically significant. The intraoperative associations for TAVR between transfusions (OR, 2.00; $P=.08)$ and TAVR approach (OR, 2.00; $P=.11)$ did not remain statistically significant within the multivariable model (Table 6).

TABLE 3. Multivariable analysis for 1-year mortality for patients undergoing transcatheter aortic valve replacement (TAVR) and surgical aortic valve replacement (SAVR)

\begin{tabular}{|c|c|c|c|}
\hline Variable & $\begin{array}{c}\text { Hazard } \\
\text { ratio }\end{array}$ & $\begin{array}{l}\text { 95\% Confidence } \\
\text { interval }\end{array}$ & $\begin{array}{c}P \\
\text { value }\end{array}$ \\
\hline Delirium (yes) & 3.023 & $1.748-5.228$ & $<.001$ \\
\hline TAVR (yes) & 2.360 & $1.269-4.389$ & .007 \\
\hline Age (per 1 year) & 1.006 & $0.976-1.036$ & .710 \\
\hline Female (yes) & 0.580 & $0.329-1.023$ & .060 \\
\hline $\begin{array}{l}\text { Society of Thoracic Surgeons } \\
\text { predicted risk of mortality } \\
\text { score (per } 1 \text { unit) }\end{array}$ & 1.099 & $1.054-1.146$ & $<.001$ \\
\hline
\end{tabular}

\section{DISCUSSION}

We found that PD is common after TAVR and SAVR, occurring in nearly one-third of patients. Importantly, patients undergoing TAVR-TF had the lowest incidence of PD when compared with SAVR or TAVR performed by any other access route. PD was associated with increased morbidity and resource use after both TAVR and SAVR and a 3-fold increase in mortality during the first year after valve replacement. The predictors of PD after TAVR or SAVR were different and based primarily upon preexisting comorbidities rather than intraoperative characteristics.

This is the largest study of PD performed specifically among AS patients undergoing valve replacement. It also examines a cohort of patients at higher risk for PD in that it includes a substantial number of patients undergoing TAVR who are older and have more comorbidities than patients typically offered traditional cardiac surgery. Our findings from the patients treated with SAVR are consistent with the literature available regarding PD after cardiac surgery with respect to incidence and inciting risk factors. And although the list of possible risk factors for PD after SAVR remains long, the variables identified in this study such as age, a history of coronary artery disease, a need for an intra-aortic balloon pump preoperatively, and greater PRBC transfusions have all previously been cited as candidate risk factors for PD with on-pump surgery. ${ }^{3,6,8,10,19}$ And although there are only a few studies available describing PD after TAVR, the data available thus far are consistent with those from this investigation suggesting that $\mathrm{PD}$ is an equally prevalent complication for TAVR, particularly when performed using alternative access techniques, ${ }^{20,21}$ It is possible that despite the fact that TAVR may be a less-invasive procedure than SAVR, 
TABLE 4. Univariable analysis of delirium among patients undergoing transcatheter aortic valve replacement (TAVR) and surgical aortic valve replacement (SAVR)

\begin{tabular}{|c|c|c|c|c|c|c|}
\hline \multirow[b]{2}{*}{ Characteristic } & \multicolumn{3}{|c|}{ TAVR } & \multicolumn{3}{|c|}{ SAVR } \\
\hline & $\begin{array}{c}\text { No delirium } \\
(\mathrm{n}=119)\end{array}$ & $\begin{array}{c}\text { Delirium } \\
(n=49)\end{array}$ & $\begin{array}{c}P \\
\text { value }\end{array}$ & $\begin{array}{c}\text { No delirium } \\
(\mathbf{n}=173)\end{array}$ & $\begin{array}{c}\text { Delirium } \\
(\mathbf{n}=\mathbf{8 6})\end{array}$ & $\begin{array}{c}P \\
\text { value }\end{array}$ \\
\hline Age (y) & $82 \pm 8$ & $81 \pm 8$ & .410 & $69 \pm 11$ & $74 \pm 10$ & $<.001$ \\
\hline Female & $68(57)$ & $24(49)$ & .390 & $69(40)$ & $39(45)$ & .420 \\
\hline Body mass index & $28 \pm 6$ & $27 \pm 5$ & .360 & $31 \pm 7$ & $31 \pm 9$ & .990 \\
\hline Society of Thoracic Surgeons predicted risk of mortality score & $9.5(5.7,14.0)$ & $9.2(6.4,12.0)$ & .920 & $2.2(1.2,4.7)$ & $4.2(2.3,7.5)$ & $<.001$ \\
\hline American Society of Anesthesiologists class $\geq 4$ & $115(97)$ & 47 (96) & $>.999$ & $110(64)$ & $70(81)$ & .004 \\
\hline New York Heart Association functional class III-IV & $103(87)$ & $44(90)$ & .800 & $81(47)$ & $58(67)$ & .002 \\
\hline Diabetes mellitus & $50(42)$ & $22(45)$ & .740 & $59(34)$ & $36(42)$ & .270 \\
\hline Hypertension & $111(93)$ & $45(92)$ & .750 & $138(80)$ & $71(83)$ & 620 \\
\hline Coronary artery disease & $100(84)$ & $43(88)$ & .640 & $70(40)$ & $44(51)$ & .110 \\
\hline Cerebrovascular disease & $35(29)$ & $17(35)$ & .580 & $34(20)$ & $23(27)$ & .210 \\
\hline Atrial fibrillation & $42(35)$ & $23(47)$ & .170 & $29(17)$ & $20(23)$ & .240 \\
\hline Chronic lung disease* & $39(33)$ & $20(41)$ & .370 & $19(11)$ & $20(23)$ & .016 \\
\hline Peripheral vascular disease & $80(67)$ & $33(67)$ & $>.999$ & $42(24)$ & $29(34)$ & .140 \\
\hline Preoperative glomerular filtration rate $(\mathrm{mL} / \mathrm{min})$ & $63 \pm 21$ & $68 \pm 38$ & .390 & $76 \pm 25$ & $71 \pm 27$ & .130 \\
\hline Chronic steroid use & $9(8)$ & $12(24)$ & .004 & $9(5)$ & $6(7)$ & .580 \\
\hline Hemoglobin (g/dL) & $11.4 \pm 1.5$ & $11.1 \pm 1.5$ & .230 & $12.8 \pm 1.9$ & $11.9 \pm 1.7$ & $<.001$ \\
\hline Albumin $(\mathrm{g} / \mathrm{dL})$ & $4.01 \pm 0.4$ & $4 \pm 0.5$ & .900 & $4.12 \pm 0.4$ & $4 \pm 0.4$ & .070 \\
\hline Procedure time (min) & $150 \pm 60$ & $160 \pm 53$ & .370 & $251 \pm 76$ & $258 \pm 66$ & .480 \\
\hline TAVR approach & & & .013 & & & \\
\hline TAVR-transfemoral & $47(39)$ & $10(20)$ & & & & \\
\hline TAVR-transapical/transaortic & $72(61)$ & $39(80)$ & & & & \\
\hline Minimum alveolar concentration volatile anesthetic & $0.95 \pm 0.13$ & $0.95 \pm 0.13$ & .980 & $0.87 \pm 0.11$ & $0.85 \pm 0.10$ & .150 \\
\hline Packed red blood cell transfusion & $42(35)$ & $25(51)$ & .080 & $120(69)$ & $74(86)$ & .004 \\
\hline
\end{tabular}

Values are presented as mean \pm standard deviation, $\mathrm{n}(\%)$, or median (first quartile, third quartile). TAVR, Transcatheter aortic valve replacement; SAVR, surgical aortic valve replacement. *Moderate/severe.

given the high-risk patient population for whom TAVR is currently restricted to as a procedural option, the incidence of PD following TAVR will remain high. The results from propensity-matched patients within this study suggest that a typical patient undergoing TAVR, with numerous comorbidities, would likely have an even higher likelihood of PD if offered an SAVR approach. The predictors of PD after TAVR remain poorly defined due to the small data sets currently available. What does appear clear based on the results of this investigation is that the association of PD with perioperative morbidity and mortality after TAVR are consistent with those reported after SAVR affecting patient outcomes within 30 days and extending out to 1 year. ${ }^{4,22}$

The implications of this study are several and highlight that increased effort may need to be directed toward the identification of PD after any cardiac surgery, including specifically TAVR procedures. This report suggests that diagnosing PD after TAVR procedures may also be difficult given the frequency of the hypoactive phenotype seen in this investigation, which can be easily overlooked but yet associated with even worse outcomes. ${ }^{9}$ This study reinforces that patients with PD represent a subgroup at higher risk for death up to 1 year postoperatively. ${ }^{8,22}$ By

TABLE 5. Multivariate analysis for delirium in patients undergoing surgical aortic valve replacement.

\begin{tabular}{|c|c|c|c|}
\hline Variable & Odds ratio & 95\% Confidence interval & $P$ value \\
\hline Age (per 1 year) & 1.043 & $1.010-1.078$ & .011 \\
\hline Society of Thoracic Surgeons predicted risk of mortality score (per 1 point) & 0.980 & $0.904-1.064$ & .630 \\
\hline Previous percutaneous coronary intervention (yes) & 1.531 & $0.761-3.078$ & .230 \\
\hline New York Heart Association functional class III-IV (yes) & 1.217 & $0.607-2.443$ & .580 \\
\hline Lung disease moderate/severe (yes) & 1.608 & $0.652-3.970$ & .300 \\
\hline Preoperative hemoglobin (per 1 unit) & 0.841 & $0.699-1.012$ & .070 \\
\hline Mitral regurgitation moderate/severe (yes) & 2.939 & $1.176-7.344$ & .021 \\
\hline Intraoperative packed red blood cells (yes) & 1.034 & $0.435-2.460$ & .940 \\
\hline Preoperative intra-aortic balloon pump (yes) & 3.509 & $0.878-14.027$ & .080 \\
\hline Intubation time $<24 \mathrm{~h}$ (yes) & 0.400 & $0.161-0.996$ & .049 \\
\hline
\end{tabular}


TABLE 6. Multivariate Analysis for Delirium in patients undergoing transcatheter aortic valve replacement (TAVR)

\begin{tabular}{|c|c|c|c|}
\hline Variable & $\begin{array}{l}\text { Odds } \\
\text { ratio }\end{array}$ & $\begin{array}{c}95 \% \text { Confidence } \\
\text { interval }\end{array}$ & $\begin{array}{c}P \\
\text { value }\end{array}$ \\
\hline Age (per 1 year) & 0.982 & $0.940-1.026$ & .420 \\
\hline $\begin{array}{l}\text { Society of Thoracic Surgeons } \\
\text { predicted risk of mortality score } \\
\text { (per } 1 \text { unit) }\end{array}$ & 0.962 & 0.899-1.029 & 260 \\
\hline Preoperative steroids (yes) & 3.944 & $1.371-11.376$ & .011 \\
\hline $\begin{array}{l}\text { TAVR via transapical or transaortic } \\
\text { approach }\end{array}$ & 2.002 & $0.851-4.710$ & .110 \\
\hline $\begin{array}{l}\text { Intraoperative packed red blood } \\
\text { cells (yes) }\end{array}$ & 2.000 & $0.919-4.352$ & .080 \\
\hline Acute kidney injury present (yes) & 3.473 & $1.191-10.129$ & .023 \\
\hline
\end{tabular}

identifying these patients in hospital, an opportunity may be provided to increase the awareness of patients and caregivers of delirium and its potential complications. Resources could be targeted to prevent hospital readmissions, and approaches could be explored to mitigate larger issues such as increased mortality and cognitive decline. ${ }^{4,22}$ From a pragmatic standpoint, this may require that delirium assessments be performed even after patients have left the ICU with different instruments such as the 3 dimensional CAM, which may be better suited than the CAM-ICU toward diagnosing PD in the stepdown setting. ${ }^{23}$

This study does suggest that maintaining a TF first approach for TAVR has the greatest potential to further decrease the incidence of PD after AVR. Because TAVR delivery systems decrease in size, patients eligible for TAVR will more likely be TF candidates, with only few patients requiring TA or TAo procedures. And although the results of this investigation and those of Eide and colleagues $^{12,21}$ suggest that TAVR-TF has the lowest incidence of PD among all AVR procedures currently performed, smaller TAVR devices now allow for TF procedures to be performed with a totally percutaneous approach, without the need for any incision or general anesthesia. Despite anesthetic use not having been shown to be a factor associated with PD in this study, the general premise that less postoperative pain and providing a lighter depth of anesthesia in older patients will reduce postoperative delirium $^{23}$ has implications for all AVR procedures and is currently the focus of an ongoing prospective trial (NCT02241655). These efforts for a minimalist approach to AVR, while not specifically addressing the predisposition or vulnerability of older patients susceptible to developing $\mathrm{PD}$, focus on minimizing the precipitating factors for PD as much as possible. ${ }^{24}$

\section{Limitations}

This study has several limitations. The patients studied in both the SAVR and TAVR cohorts for the development of
PD were quite different with respect to the severity and frequency of their comorbidities, potentially biasing the frequency of PD within each cohort. Assessments for PD were done for patients while in the ICU only, and by the CAM-ICU only. Although the CAM-ICU is highly specific, its sensitivity is less, predisposing to underreporting of $\mathrm{PD}$ for both the TAVR and SAVR groups.

The relatively small number of patients with PD, particularly in the TAVR, cohort limited the ability to identify clinically significant, independent predictors for delirium after TAVR. Greater numbers of patients will be required to better delineate independent risk factors for PD for TAVR and these types of patients. Given the association between PD and later cognitive impairment, future studies should incorporate cognitive and frailty assessments with PD because these metrics are particularly valuable to this older population.

Lastly, because this was a retrospective analysis for PD, it is impossible to account for the many confounding variables that exist for the assessment of PD and future prospective studies will be required to further explore the findings of this investigation.

\section{CONCLUSIONS}

PD occurs commonly after SAVR and TAVR and is associated with increased perioperative morbidity and resource use. Moreover, the development of PD is associated with increased mortality at both 30 days and over the first year after procedure. Although further studies are needed to confirm and extend the findings of this investigation, addressing PD and any potentially modifiable risk factors for its development has the potential to reduce this specific postoperative complication and may also influence other associated adverse outcomes after AVR therapy.

\section{Conflict of Interest Statement}

Dr Damiano reports consulting fees from Atricure, lecture fees and grant support from Edwards and On-X Lifesciences, and grant support from Thrasos Inc. Dr Lindman reports consulting fees from Roche Diagnostics. Dr Lasala reports consulting fees from Boston Scientific; equity ownership in Abiomed and DirectFlow; and lecture fees from Abiomed, St. Jude, Boston Scientific, and Eli Lilly. Dr Melby reports consulting fees from On-X and lecture fees from ClearFlow. All other authors have nothing to disclose with regard to commercial support.

You can watch a Webcast of this AATS meeting presentation by going to: http://webcast.aats.org/2015/Video/ Monday/04-27-15_608_1545_Maniar.mp4.

\section{References}

1. American Psychiatric Association. Diagnostic and statistical manual of mental disorders. 5th ed. Arlington, VA: American Psychiatric Association; 2013. 
2. Avidan MS, Fritz BA, Maybrier HR, Muench MR, Escallier KE, Chen Y, et al. The Prevention of Delirium and Complications Associated with Surgical Treatments (PODCAST) study: protocol for an international multicenter randomized controlled trial. BMP Open. 2014;4:e005651.

3. Jung P, Pereira MA, Hiebert B, Song X, Rockwood K, Tangri N, et al. The impact of frailty on postoperative delirium in cardiac surgery patients. $J$ Thorac Cardiovasc Surg. 2015;149:869-75.

4. Rudolph JL, Inouye SK, Jones RN, Yang FM, Fong TG, Levkoff SE, et al Delirium: an independent predictor of functional decline after cardiac surgery. J Am Geriatr Soc. 2010;58:643-9.

5. Zaal IJ, Devlin JW, Peelen LM, Slooter AJ. A systematic review of risk factors for delirium in the ICU. Crit Care Med. 2015;43:40-7.

6. Gottesman RF, Grega MA, Bailey MM, Pham LD, Zeger SL, Baumgartner WA, et al. Delirium after coronary artery bypass graft surgery and late mortality. Ann Neurol. 2010;67:338-44.

7. Ely EW, Shintani A, Truman B, Speroff T, Gordon SM, Harrell FE Jr, et al. Delirium as a predictor of mortality in mechanically ventilated patients in the intensive care unit. JAMA. 2004;291:1753-64.

8. Whiltlock EL, Torres BA, Lin N, Helsten DL, Nadelshon MR, Mashour GA, et al. Postoperative delirium in a substudy of cardiothoracic surgical patients in the BAG-RECALL clinical trial. Anesth Analg. 2014;118:809-17.

9. Postoperative delirium in older adults: best practice statement from the American Geriatrics Society. J Am Coll Surg. 2015;2:136-48.

10. Koster S, Hensens AG, Scuurmans MJ, van der Palen J. Consequences of delirium after cardiac operations. Ann Thorac Surg. 2012;93:705-11.

11. Smith CR, Leon MB, Mack MJ, Miller DC, Moses JW, Svensson LG, et al. Transcatheter versus surgical aortic-valve replacement in high-risk patients. $N$ Engl J Med. 2011;23:2187-98.

12. Comparison of transfemoral transcatheter aortic valve replacement performed in the catheterization laboratory (minimalist approach) versus hybrid operating room (standard approach): outcomes and cost analysis. J Am Coll Cardiol Cardiovasc Interv. 2014;7:898-904.

13. Nickalls RW, Mapleson WW. Age-related iso-MAC charts for isoflurane, sevoflurane and desflurane in man. Br J Anaesth. 2003;91:170-4.

14. Ely EW, Inouye SK, Bernard GR, Gordon S, Francis J, May L, et al. Delirium in mechanically ventilated patients: validity and reliability of the confusion assessment method for the intensive care unit (CAM-ICU). JAMA. 2001;286:2703-10.

15. McNicoll L, Pisani MA, Ely EW, Gifford D, Inouye SK. Detection of delirium in the intensive care unit: comparison of confusion assessment method for the intensive care unit with confusion assessment method ratings. J Am Geriatr Soc. 2005; 53:495-500.

16. Peterson JF, Pun BT, Dittus RS, Thomason JW, Jackson JC, Shintani AK, et al. Delirium and its motoric subtypes: a study of 614 critically ill patients. J Am Geriatr Soc. 2006;54:479-84

17. Pandharipande P, Cotton BA, Shintani A, Thompson J, Costabile S, Truman Pun B, et al. Motoric subtypes of delirium in mechanically ventilated surgical and trauma intensive care unit patients. Intens Care Med. 2007;33:1726-31.

18. Kappetein AP, Head SJ, Genereux P, Piazza N, van Mieghem NM, Blackstone EH, et al. Updated standardized endpoint definitions for transcatheter aortic valve implantation: the Valve Academic Research Consortioum-2 consensus document. J Am Coll Cardiol. 2012;60:1438-54.

19. Trabold B, Metterlein T. Posoperative delirium: risk factors, prevention and treatment. J Cardiothorac Vasc Anesth. 2014;28:1352-60.

20. Tse L, Bowering JB, Schwarz SKW, Moore RL, Burnds KD, Barr AM, et al. Postoperative delirium following transcatheter aortic valve implantation: a historical cohort study. Can J Anesth. 2015;62:22-30.

21. Eide LSP, Ranhoff AH, Fridlund B, Haaverstad R, Hufthammer KO, Kuiper KK, et al. comparison of frequency, risk factors, and time course of postoperative delirium in octogenarians after transcatheter aortic valve implantation versus surgical aortic valve replacement. Am J Cardiol. 2015;115:802-9.

22. Wilbring M, Tugtekin SM, Alexiou K, Simonis G, Matschke K, Kappert U. Transapical transcatheter aortic valve implantation vs conventional aortic valve replacement in high-risk patients with previous cardiac surgery: a propensityscore analysis. Eur J Cardiothorac Surg. 2013;44:42-7.

23. Marcantonio ER, Ngo LH, O'Connor M, Jones RN, Crane PK, Metzger ED, et al. 3D-CAM: derivation and validation of a 3 minute diagnostic interview for CAMdefined delirium: a cross-sectional diagnostic test study. Ann Intern Med. 2014; 161:554-61.

24. Chan MT, Cheng BC, Lee TM, Gin T, CODA Trial Group. BIS-guided anesthesia decreases postoperative delirium and cognitive decline. J Neurosurg Anesthesiol. 2013;25:33-42.
Key Words: TAVR, delirium, cardiac surgery, aortic stenosis, aortic valve replacement

\section{Discussion}

Dr Lars G. Svensson (Cleveland, Ohio). Your work raises more questions than answers concerning the whole issue of neurologic injury after either transcatheter aortic valve repair (TAVR) or aortic valve replacement (AVR). Ideally it would have been interesting to see a comparison using postoperative diffusion-weighted magnetic resonance imaging (MRI) and higher executive function neuropsychologic testing.

I could ask questions specifically related to postoperative testing to diagnose the cause of the symptom of delirium; however, I would rather encourage you to do a prospective study examining MRI and neurocognitive higher function testing.

As we try to understand postoperative consequences of TAVR, it is important to note that MRI brain lesions are associated with a greater risk of recurrent events and later development of Alzheimer disease or dementia. Indeed, Ghanem found that 1 of 8 patients after TAVR at 2 years had deterioration of Repeatable Battery for the Assessment of Neuropsychological Status assessment. Related also to your study, Rodes-Cabau found no difference between a transapical versus transfemoral approach.

You showed differences in delirium rates, yet the key is higher neurocognitive function at 30 days. That would be an important study but should also be supported by MRI evaluation. For example, we don't know what role anesthesia may have played.

In a study from my group that will be shortly published in this journal, we found that both tests are needed because neurocognitive testing may not correlate with any MRI brain lesions, and alternatively, positive brain lesions on MRI may not be detected by neurocognitive testing.

I have 1 question: Will you do a prospective study to better elucidate the neurologic injuries that can be associated with the delirium?

Dr Maniar. The simple answer to your question is yes. You raise several issues in regard to postoperative delirium. It is not clear whether postoperative delirium is for a symptom of something else occurring within a patient. MRI-based assessments are going to be what is needed to determine that.

We are going to see some of these data come out through the SENTINEL trial where embolic filters are placed in patients during TAVR, and we are going to have the imaging available to us. We will have to focus on prospective studies that also include neurocognitive testing. As you know, there is a suggestion that patients with impaired neurocognitive assessments preoperatively 
are also then part of the subset that have most of the problems postoperatively. I think it will be 2-fold: looking at true incidence, and helping elaborate on modifiable or identify new risk factors.

Regarding anesthesia, that is really going to be an interesting area. TAVR has now moved into the second generation where now the majority of transfemoral procedures are going to be done percutaneously. There is also a movement afoot by our anesthesia colleagues in a multicenter trial that we're participating in where sedation is going to be individualized to a given patient looking at monitoring brain function during the anesthetic procedure in an attempt to not overanesthetize some of our patients.

We are going to see better testing, better imaging, and I think more fine-tuning of our anesthesia, and it will be interesting to see the differences that play out here.

Dr Svensson. Thank you.

\title{
EDITORIAL COMMENTARY
}

\section{Delirium after aortic replacement: A transvalvular approach is no panacea}

\author{
Hilary P. Grocott, MD, FRCPC
}

\footnotetext{
From the Departments of Anesthesia \& Perioperative Medicine and Surgery, University of Manitoba St Boniface Hospital, Winnipeg, Manitoba, Canada

Disclosures: Author has nothing to disclose with regard to commercial support.

Received for publication Nov 10, 2015; accepted for publication Nov 12, 2015; available ahead of print Dec 18 , 2015.

Address for reprints: Hilary P. Grocott, MD, FRCPC, Department of Anesthesia \& Perioperative Medicine, University of Manitoba St Boniface Hospital CR3008, 369 Tache Ave, Winnipeg, Manitoba, Canada R2H 2A6 (E-mail: hgrocott@sbgh.mb.ca)

J Thorac Cardiovasc Surg 2016;151:823-4

$0022-5223 / \$ 36.00$

Copyright (c) 2016 by The American Association for Thoracic Surgery

http://dx.doi.org/10.1016/j.jtcvs.2015.11.018
}

Postoperative delirium (PD) is an increasingly recognized complication of all surgical procedures, both minimally invasive and other. Surgery for aortic valve replacement is no exception, and Maniar and colleagues ${ }^{1}$ provide the largest study to date of PD after transcatheter aortic valve replacement (TAVR). Despite the relatively less invasive nature of TAVR, compared with open surgical aortic valve replacement (SAVR), the overall incidence of PD in this retrospective study was essentially the same $(30 \%$ for SAVR vs $29 \%$ for TAVR; $P=.40$ ). On the surface, this result may seem disappointing, ie, that a relatively "less invasive" procedure would not lower the incidence of this serious complication. However, the TAVR approaches varied considerably (including transfemoral, transapical, and transaortic), and in a subset analysis of the transfemoral approach, which is arguably the least invasive, the PD incidence was, in fact, lower than that with SAVR $(18 \%$ vs $33 \%$, respectively; $P=.025$ ).

However, the lack of difference in the primary comparison, even ignoring this subset analysis, may be due to the multifactorial nature of delirium. The etiology

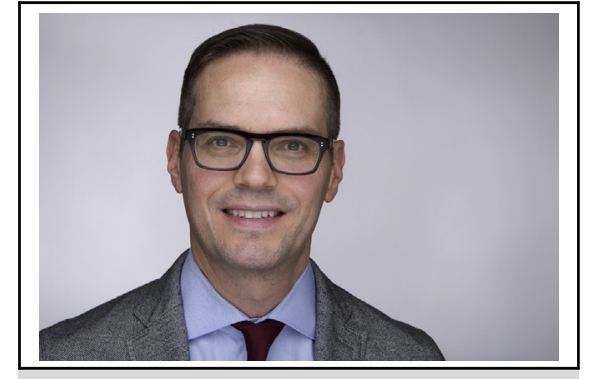

Hilary P. Grocott, MD, FRCPC

Central Message

Delirium remains an important neurologic sequela of aortic valve replacement, despite use of a more minimally invasive transvalvular approach.

See Article page 815 .

and pathophysiology of PD is incredibly complex; it may depend as much on nonsurgical factors as on actual surgical trauma and its associated inflammatory response, which is commonly included in discussions of delirium pathophysiology. Similarly, this complexity may partially explain the lack of PD difference in the 2 groups. Inflammation from TAVR is thought to be lower, compared with SAVR, ${ }^{2}$ but it is only one possible target for addressing delirium. Further, the importance of inflammation as an etiologic factor in PD has been questioned recently, given the failure of high-dose steroids to mitigate its occurrence. ${ }^{3}$ 

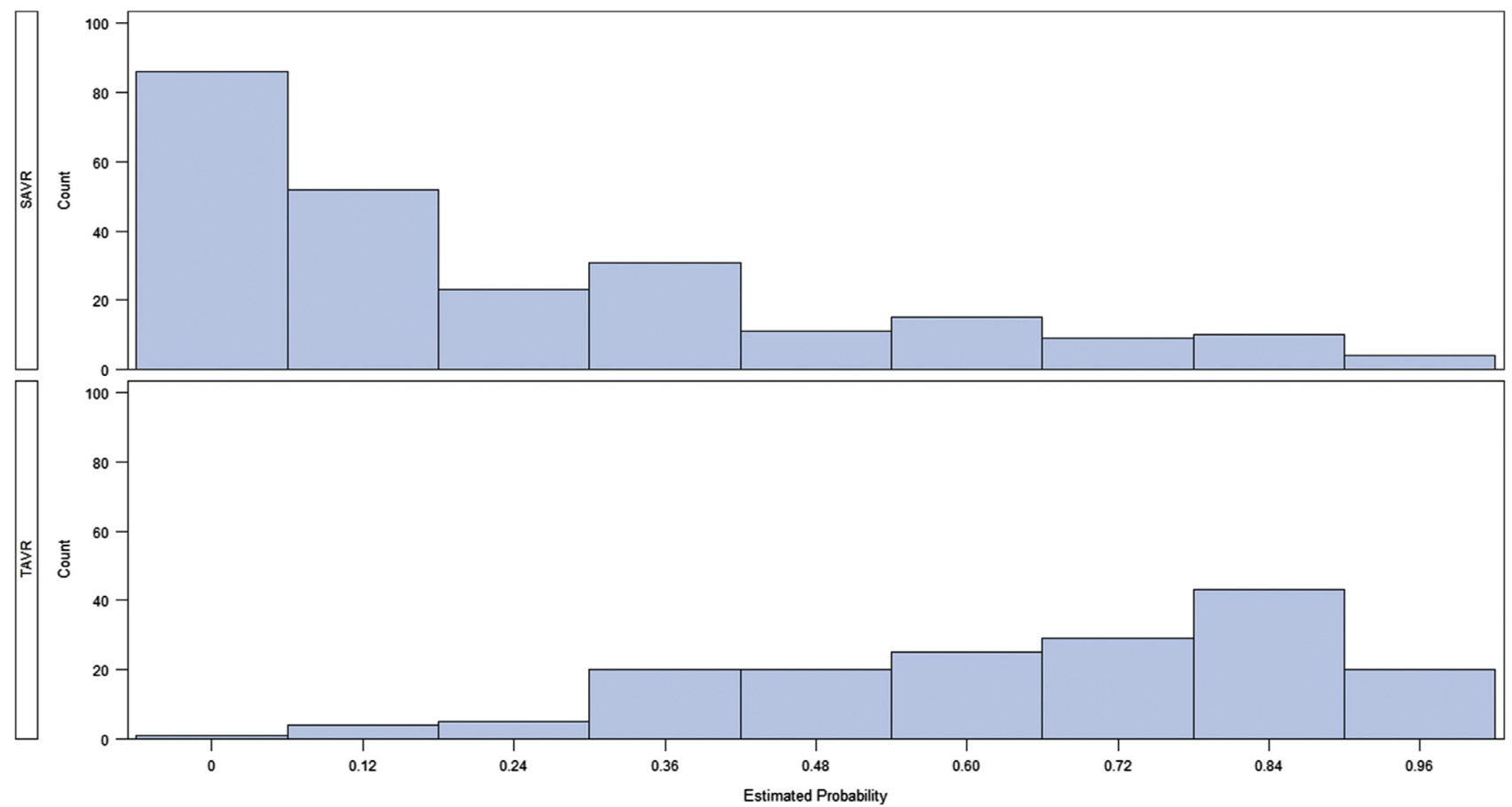

FIGURE E1. Covariate balance showing the standardized difference between transcatheter aortic valve replacement $(T A V R)$ and surgical aortic valve replacement $(S A V R)$ before and after propensity score matching.

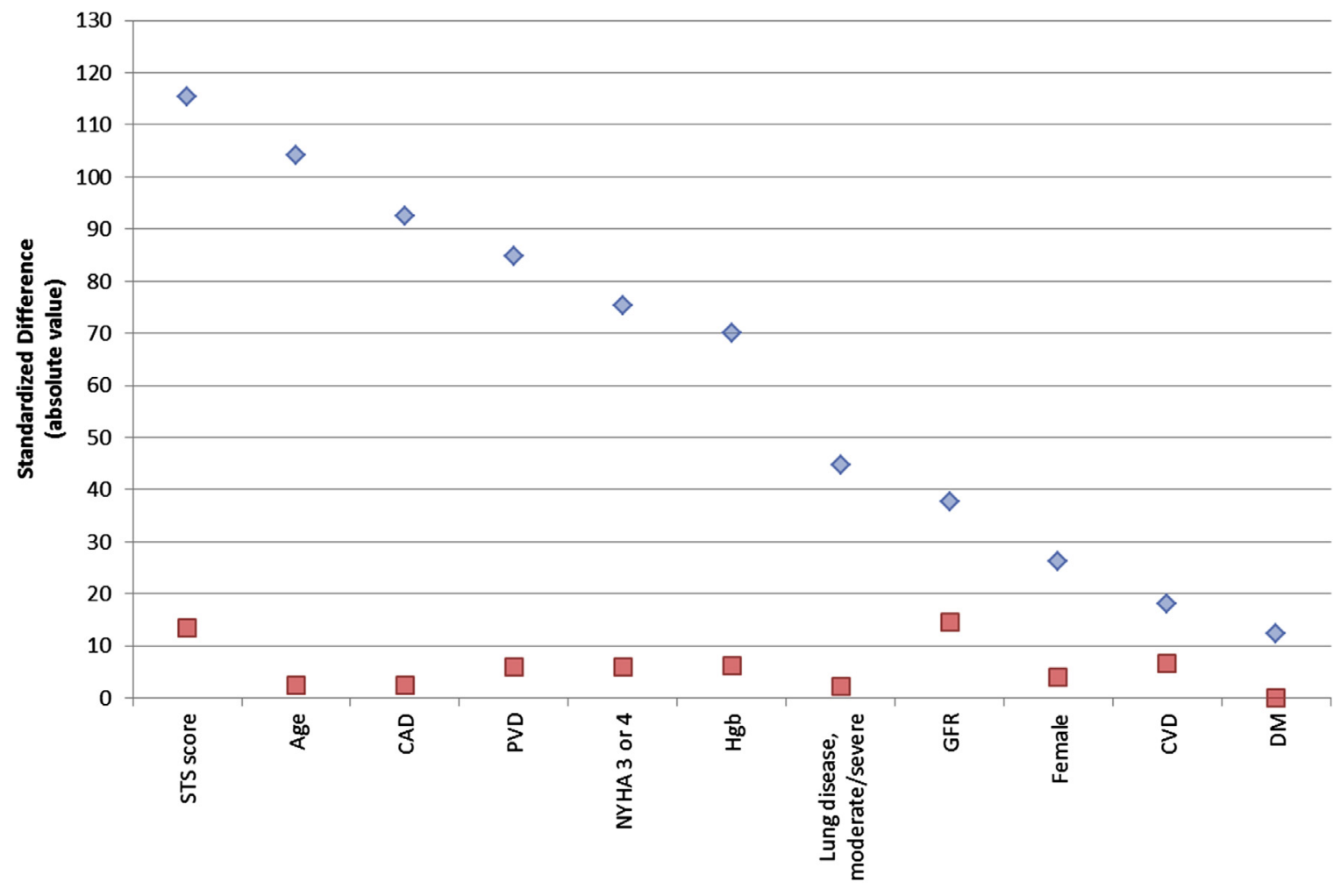

$\diamond$ Before $\square$ After

FIGURE E2. Distribution of propensity scores before matching to evaluate overlap. STS, Society of Thoracic Surgeons; $C A D$, coronary artery disease; $P V D$, peripheral vascular disease; NYHA, New York Heart Association, $H g b$, hemoglobin; GFR glomerular filtration rate, $C V D$, cerebrovascular disease; $D M$, diabetes mellitus. 
TABLE E1. Kaplan-Meier estimates of mortality among patients undergoing transcatheter aortic valve replacement (TAVR) and surgical aortic valve replacement (SAVR)

\begin{tabular}{|c|c|c|c|c|c|c|}
\hline \multirow[b]{2}{*}{ AVR type } & \multirow[b]{2}{*}{ Time from implant } & \multicolumn{2}{|c|}{ Without delirium } & \multicolumn{2}{|c|}{ With delirium } & \multirow[b]{2}{*}{$P$ value } \\
\hline & & Survival $\%$ & 95 $\%$ Confidence interval & Survival $\%$ & $\mathbf{9 5} \%$ Confidence interval & \\
\hline \multirow[t]{3}{*}{ TAVR } & $30 \mathrm{~d}$ & 98.3 & $93.4-99.6$ & 87.8 & $74.8-94.3$ & .029 \\
\hline & $6 \mathrm{mo}$ & 89.5 & $82.2-93.9$ & 79.1 & $64.7-88.2$ & .110 \\
\hline & $1 \mathrm{y}$ & 80.4 & $71.1-87.0$ & 66.4 & $50.0-78.5$ & .090 \\
\hline \multirow[t]{3}{*}{ SAVR } & $30 \mathrm{~d}$ & 1.00 & $1.00-1.00$ & 95.3 & $88.1-98.2$ & .041 \\
\hline & $6 \mathrm{mo}$ & 98.8 & 95.4-99.7 & 88.4 & $79.4-93.6$ & .003 \\
\hline & $1 \mathrm{y}$ & 97.3 & $92.7-99.0$ & 82.8 & $72.6-89.5$ & .001 \\
\hline
\end{tabular}

$A V R$, Aortic valve replacement; TAVR, transcatheter aortic valve replacement; $S A V R$, surgical aortic valve replacement. 